\title{
ХРОНИКА
}

\section{ТРЕТЬЯ ВСЕССЮЗНАЯ КОНФЕРЕНЦИЯ МВО СССР ПО РАДИОЭЛЕКТРОНИКЕ}

С 22 по 27 января 1959 г в Киевском государственном университете имени Т. Г. Шевченко проходила Третья Всесоюзная конференция Министерства высшего образования СССР по радиоэлектронике, посвященная 100-летию со дня рождения великого ученого и изобретателя радио А. С. Попова.

Конференция собралась в кануі XXI-го съезда КПСС, знаменующего грандиозный технический прогресс нашей страны в предстоящем семилетин во всех отраслях народного хозяйства.

В работе конференции приняли участие около 500 представителей высших учебных заведений и научно-исследовательских учреждений.

Первое пленарное заседание .22 января открыл ректор Киевского университета академик АН УССР И. Т.Швец. Подчеркнув роль работников наукі в свете тезисов доклада $\mathrm{H}$. C. Хрущева на XXI съезде КПСС, И. Т. Швец отметил, что конференция демонстрирует достижения в области радиоэлектроники и ее применения. Ярким усиехом радиоэлектроники является разработка комплекта радиотехнической аппаратуры, установленной на трех искусственных спутниках Земли и на космической ракете.

С приветственным словом от Всесоюзного научно-технического общества им. А. С. Попова к присутствующим обратился Я. М. Сорин - ученый секретарь Оргкомитета по проведению столетнего юбилея со -дня рождения А. С. Попова. В выступлении Я. М. Сорина, в частности отмечалась важность исследований в области повышения надежности радноэлектронной аппаратуры.

Пленарное заседание закончилось докладом В. К. Ткача (Харьков) «Некоторые результаты применения радиоэлектроники к изучению биологических сред», в котором автор изложил один из новых методов исследования устойчивости белковых структур крови путем изучения нестационарного теплообмена их растворов в высокочастотном поле.

Приведенные в докладе материалы получены в результате применения мегодов радиоэлектроники для изучения динамики развития раковых заболеваний у людей и развития экспериментальной лучевой болезни у животных, вызванной воздействием некоторых видов ионизирующи излучений.

Работа конференции проходила в ceми секциях, на которых было заслушано более 150 докладов о результатах научно-исследовательских и практическнх работ в области радноэлектроники, проведенных в вузах, научно-исследовательских организациях и предприятилх Москвы, Ленинграда, Киева, Харькова, Горького, Томска, Таганрога, Саратова и др. городов нашей страны.

$\mathrm{Ha}$ секции электроники СВЧ было заслушано 26 докладов и сообщений.

В докладах К. Я. Лнждвоя (Кнев), И. И. Антакова и Васильева Р. П. (Горький), Б. Н. Бокова (Горький), рассматривались новые приборы с циклоидальными и трохоидальными траекториями в скрещенных полях.

Значительный вклад в теорию фазохронного взаимодействия представляют работы, освеценные в докладах А. В. Гапонова (Горький), И В. Акаловского (Киев), В. Н. Гинзбурга, В. А. Солнцева, А. С. Тагера (Москва), а также в сообщения В. А. Сосунова (Саратов).

Значительный интерес представляют работы по параметрической регенераIии в электронных пучках, изложенные Д. К. Акулиной, С. А. Ахмановым, А. С. Горшковым, И. Г. Трофименко (Москва), Ергаковым В. С., Шапошниковым А. А. (Горький), а также в сообщении В. Н. Лопухина (Москва).

По цокладам Рапопорта $\Gamma$. Н. (Кнев) и Геккера И. Г. (Москва) секция отметила перспективность исследования по повым методам к. п: д. генераторов CBЧ.

Важные уточнения в теорию ЛБВ и усовершенствование мсгодики ЛБВ приведены в докладах Гвоздовера С. Д., Солодарь Е. Г. (Москва), Каца А. М. и Цейтлина А. M. (Саратов).

Қрупным достижением отечественной электроники секция считает разработку мощного усилительного клистрона длІ 
радиорелейных линий, о которой сообщено в докладе Кармазина Б. Г. (Москва) «Разработка мощного усилительного клистрона нелрерывного действия для радиорелейных линий связи». Длч расчета приборов такого типа прнменялась методика, изложенная в докладе Акментыньша Я. Я., Зусмановского С. А., Хапланова 3. И. (Москва).

Значительный научный интерес представляет работа по экспериментальному цоказательству возможности фокусировки заряженных частиц высокочастотными полями, изложенная в докладе Браво-Животовского Д. М., Еремина Б. Г., Загрядского Е. В., Миллера М. Н., Моченева С. Б. (Г'орький) «Экспериментальное исследование возможности фокусировки пучков заряженных частищ высокочастотными полями».

Секция отметила развитие эффективных методов расчета в применении $\mathrm{k}$ конкретным задачам, в частности, метод нелинейной теории по докладу Қлимонтөвича Ю. Л. (Москва) « Геория нелинейных плазменных колебаний и некоторые ее применения к анализу работы электронно-лучевых приборов».

На секции общей электрокики заслушано много интересных, содержательных докладов, в основном посвященных оптике электронных пучков.

В докладе Голубкова П. В. и Козлова Н. Г. (Саратов) «Экспериментальное исследование распределения скоростей электронов в электронных потоках» методом цилиндрического конденсатора Юза-Рожанского исследовалось распределение электронов по скоростям $\mathbf{3}$ потоке, выходящем из электронного прожектора.

Тараненко В. П. (Киев) в докладе «O применении ионных ловушек в электронно-оптических системах генераторов сантиметровых волн» сообщил - результатах исследований нейтрализацин электронного пространственного заряда положительными ионами остаточных газов в условиях высокого вакуума.

В докладе Овчинникова И. К., Зинченко Н. С. (Харьков) «Зондовый метод исследования аксиально-симметричных пучков электронов» для измерения параметров интенсивных электронных пучков был предложен метод вибрнрующего зонда.

Цейтлин $M$. Б. (Саратов) изложил результаты работы «Ограничение тока в пучках конечной длины» при наличии достаточно большого магнитного поля, препятствующего расплыванню пучка.

Кононенко Қ. И. и Соболь Г. А. (Харьков) в докладе «Детекторныс свойства газоразрядной плазмы» привели результаты экспериментального исследования детекторных свойств газоразрядной плазмы в зависимостн от режима разряда, давления газа, частоты детектируемых сигналов и местоположения и ориентации детектирующих электродов.
Голуб Г. Л., Тарасов П. А., Губанова Л. И. (Москва) в докладе «Цирокополосные осциллографические трубки для регистрации миллимикросекундных электрических импульсов и колебаннӥ СВЧ» сообщили о разработке трубок для регистрации СВЧ колебаний в диапазоне регистрируемых частот до 10000 мег

В доклаце Анисимовой Ю. Н., Выставкина А. Н. (Москеа) «Моделирование траекторий релятивистских электронов в магнитном ондуляторе» показана возможность моделированил траектории релятивистских электронных пучков в магнитных полях любой конфигурации низковольтными электронными пучками при пониженных магнитных полях.

Герштейном Г. $M$. (Саратов) было рассмотрено «Моделирование электричеєкого поля с помощью измерения наведенного тока̇».

В сообщении Левицкого С. M. Шашурина И. П. (Киев) рассматривалось «Измерение концентрации зарядов із плазме методом СВЧ зонда».

В докладе Соболева В. Д., Урлаповой М. Н. (Москва) рассматрнвалось «Измерение термоэлектронной эмиссии оксидного катода в ионных прнборах».

Вопросу соотношения подобия для широкого класса нерелятивистских электровакуумных приборов был посвящен доклад Тиктина С. А. (Харьков) «Электрические и тепловые соотношения прі моделировании высоковакуумных электронных приборов высоких и ссверхвысоких частот».

На секщие электродиналики СВУ было заслушано более. 30 докладов и сообщений по актуальным вопросам теоретических и экспериментальных исследований СВЧ систем.

Теорни, расчету и экспериментальному исследованию замедляюших спстем были посвящены доклады: Г. И. Гладышева (Киев) «Диафрагмированные волноводы с дополнительными элементами связн». 3. И. Тараненко (Киев) «Волнообразно изогнутый волновод как замедляющая система с положительної дисперсией»; В.. Д. Иванова, В. С. Михалевского (Ростов) «Замедляющая система спирального тнпа при наличи плазмы»; В. А. Слюсарского (Харьков) «Некоторые методы расчета замедляющих систем типа спираль - ребристая структура»; В. Д. Иванова, В. С. Михалевского (Ростов) «Замедляющая снстема спирального типа при наличин плазмы»; Н. М. Чиркина (Таганрог) «Коаксиальный волновод со спнральным желобом на внутреннем проводнике» и «К теории замедляющих систем»; Б. М. Булгакова (Харьков) «Влиянне свойств магнитодиэлектрика на распространение электромагнитных волн в замедляющей системе типа спираль-магнитодиэлектрик»; Ю. Г. Альгшулера (Саратов) «K теорин встречноштыревых замедляющих систем» іп др. 
Ряд докладов был посвящен теоретическим и экспериментальным вопросам, связанным с применением линий передачи на СВЧ: А. Г. Савченко (Mосква) «Нерегулярные волноводы»; В. С. Ильнн (Саратов) «Вариационный метол расчета четырехполюсных неоднородностей в прямоуголыных волноводах»; В. В. Тяжелов (Москва) «Приближенный расчет влияния неоднородностей на однопроводных линиях передачи»; В. М. Седых (Харьков) «Затухание в Н-волноводах»; В. М. Седых, А. М. Зоркин (Харьков) «Затухание в крестообразных волноводах» и др.

Вопросы теории и применения резонаторных систем на СВЧ были рассмотрены в докладах: Б. П. Петрова (Таганрог «К вопросу о пространственных обертонах в резонаторах. Блуждающий резонанс»; А. И. Терещенко (Харьков) «Зависимость свойств резонаторной системы магнетрона от форм резонатора»; B. А. Короткина, А. И. Терещенко (Харьков) «О возможностн улучшения параметров резонаторной системы магнетрона»; А. С. Бондарева (Киев) «Деформация электромагнитного поля в резонаторах с неидеальными стенками»; М. А. Фурсаева «О дисперсии резонаторной замедляющей системы с двойными связками» и др.

Вопросы СВЧ измерений нашли свое отражение в докладах: К. П. Яцука (Харьков) «Использование медленных поверхностных волн для измерения циэлектрических проницаемостей вещества на сверхвысоких частотах»; P. Н. Бондаренко, Е. Д. Майбороды, В. И. СтрнХи (Киев) «Измерение полного входного сопротивления детектора по методу сверхвысокочастотных нагрузочных характеристик»; М. М. Райнера, И. Д. Хмелькова «Способ измерения добротности» и др.

Некоторые вспросы техннки СВЧ освепены в докладах: Г. А. Орловского (Қиев) «О возможносіи нспользования неоднородных линий в качестве колеба тельной системы генераторов СВЧ»; В. П. Сазонова (Москва) «Широкополосное согласование коаксиальной линии со спиралью»; Я. $M$. Туровера (Москва) «Согласование коаксиальной линии с прямоугольным волноводом при наличия конической антенны» и др.

На секции квантовой радиотехники и радиоспектроскопии было заслушано 18 докладов. С большим интересом присутствуюшие выслушали доклад В. А. Гапонова (Горький) «Об ударных электромагнитных волнах в ферритах».

В докладе Л. Л. Мясникова (Горький) «О квантовом магнитно-акустическом эффекте» рассматривался лдерный магнитный резонанс и электронный парамагнитный резонанс при ультразвуковом возбуждении кристаллической решетки.

В. M. Файн (Горький) в докладе «К теорни когерентного спонтанного излученя» рассмотрел пекоторье вопросы теории когерентного спонтанного излучения в радиодиапазоне и показал, что взаимодействие через общее поле излучения приводит к сдвигу собственных частот системы.

Перспективам использования явлений в ферритах для усиления и генерирования сверхвысоких частот были посвящены доклады В. П. Тычинского (Mосква), Ю. Т. Деркача (Москва), И. А. Дерюгина и М. А. Сигала (Киев).

Ю. С. Константинов (Москва) сделал сообщение: «Аппаратура для измерення химических сдвигов ядерного магннтного резонанса».

Я. М. Шамфаровым (Харьков) изложены результаты работы «Высокочувствительный парамагнитный радиоспектрометр на частоте 900 мгцц», в котором применена стабилизация частоты сигнального клистрона по измерительному резонатору, а также автоподстройка чатоты местного гетеродина.

В докладе Сучкина Г. Л. (Горький) «Теория параметрического смесителя на магнитных полупроводниках» был дан анализ резонансного и нерезонансного параметрического смесителя на ферриTax.

Сведения пб устройстве, принципе действия и технических возможностях атомно-лучевых стандартов частоты были изложены в докладе И. А. Калядиной, В. П. Лагузова, Г. И. Рукмана, Я. А. Юхвидина (Москва): «Современные атомно-лучевые способы стабилизации сверхвысоких частот».

На секции распространения радиоволн и радиоастрономии было заслушано 16 докладов.

Большая часть докладов была посвя щена вопросам нзлучения и распространения радноволн в плазме и, в частности, в ионосфере.

Доклад Г. Г. Гетманцева (Горький) $« \mathrm{O}$ нетепловом космическом радиоизлучении» был посвящен объяснению радиоизлучения плоской составляющей на основе магнитно-тормозного радиоизлучения релятивистских (космических) электронов.

В докладе В. В. Железнякова (Горький) «О магнитно-тормозном излучении и резонансном поглощении в плазме» была рассмотрена связь резонансного поглощения обыкновенных и необыкновенных электромагнитных волн на настотах, приблизительно кратных гирочастоте, с магнитно-тормозным излучением плазменных электронов, а также рассмотрен вопрос об интенсивности излучения электронных потоков, движущихся в магнитном поле.

Значи'ельный интерес слушатели проявили к работе В. Д. Гусева, С. Ф. Миркотина, Л. А. Драчева, Ю. В. Юерезина, М. П. Кияновского (Москва) «Результаты исследования параметров нерегулярной ионосферы фазовым методом», в которой исследовались крупные неоднородности и их движение в ионосфере методом регистрации измене- 
ний фазового пути сигнала, отраженного от ноносферы.

Во втором докладе этих же авторов было сообщено «О методике корреля. ционной обработки флюктуаций при наличии медленно меняющейся нестацио нарной составляющей».

Интересные результаты работ по радиолокации Луны, были сообщены М. М Кобриным (Горький).

В докладе Б. С. Шапиро «Исследование распределения ионизации с высотой в ионосфере методом вертикального раднозондирования» рассматривался предложенный автором метод определения геометрических параметров ионосферных слоев по табличным ионосферным данным.

Б. А. Бенедиктов, Н. А. Митяков (Горький) рассмотрели «Учет влиянил магнитного поля Земли при излученин».

Доклад А. А. Семенова, Г. А. Карпеева (Москва) «О связи частоты флюктуащий амплитуды поля со скоростью дрейфа \неоднородностей» был посвящен исследованию вопроса с учетом лрейфа неоднородностей и хаотических скоростей рассеивателей.

Ду Лен-Яо, А. Н. Малахов, В. М. Плечков, В. А. Разин, В. А. Рахлин, Қ. С. Станкевич, К. M. Стрежнева, Тан ІШоу-Пэ, В. С. Тромцкий, В. В. Хрулев, Н. M. Цейтлин (Горький) в докладе: «Наблюдение кольцеобразного затмения Солнца 18.IV. 1958 г. на волнах $1,63,3,2$ и 10 см» сообщили о построении моделей Солнца на оснивании измерений интенсивности : солнечного радиоизлучения во время затмения.

Доклады «Радиоэлектронная часть солнечных магнитографов НИЗМИР Гица И. Д., Иошпа Б. А., Могилевского Э. И. и «Электрические светомодуляторы солнечных магнитографов НИЗМИР» Жулина И. А. были посвяшены электронике солнечных магнитографов.

В. Е. Қашпаровский рассмотрел «Новый метод измерения проводимости почв по затуханию волн и результаты сопоставления измерений с известными методами».

Я. Н. Лихтер, Г. И. Терина доложнли «О статических свойствах напряженности поля атмосферных радиопомех». Б. Н. Гершман (Горький) выступил с докладом «К теории распространения низкочастотных волн в магнитноактивной плазме».

На секध"и общей радиотехники было заслушано 11 докладов и сообщений, вызвавших оживленные дискуссии, что свидетельствовало о большом интересе присутствующих к рассматриваемым вопросам.

Секция отметила доклад В. А. Ковальчука (Киев) «Деление частоты в двухконтурных автогенераторах». В связи с большими успехами, достигнутыми в области получения высокостабильных колебаний диапазона СВЧ, предложенный автором метод позволяет получить колебания такой же стабильности в других радиочастотных диапазоіах.

В. А. Малышев (Таганрог) сделал доклад «О решении проблемы теории автогенераторов с одним нелинейным элементом».

Г. Л. Соболевым сделано сообщение «Қ вопросу об автостабилизации периода повторения импульсов релаксационных генераторов».

В докладе В. ГІ. Ковалева (Москва) «Определение модуля и фазы напряженностей электрического поля на СВЧ помощью одновременного измерения временных компонент поля» был предложен метод измерений, отличающийся от известных возможностыю одновременного автоматического измерения временных компонент поля и его схемное решение на примере лабораторной установки.

Предметом сообщения Е. А. Домановой (Харьков) было «Исследование аттенюатора, основанного на эффакте изменения концентрации носигелей тока в тонком полупроводнике, находящемся в магнитном поле, при прогскании через него электрического токэ».

Доклад М. М. Грацианской (Москва) «Видимость сигнала на экране электропно-лучевой трубкн» был посвящен исследованию эксплуатационных характеристик экранов электронно-лучевых трубок.

В докладе А. А. Тютина (Киев) «Элементы телевизионного счетно-решаюшего устройства для получения послойных, a также объемных рентгеновских изображений» рассматривалась одна из возможных схем нового метода рентгенотехники, предложенного в 1956-1957 гг. чл.-корр. АН УССР С. И. Тетельбаумом.

Сообщение А. А. Бессонова (Ленннград) «Оценка надежностн радиоэлектронных устройств» относилось $k$ акті альной проблеме надежности радноаппаратуры, которая, к сожалению, была представлена на секции только этим сообщением.

Доклад Лянного В. П. (Кнев) «Исследование погрешностей интеграто$\mathrm{pa}$ для осуществления оптимальной амплитудно-фазовой модуляции и их коррекция» был посвящен исследованию погрешностей интегратора за счет конечных пределов интегрирования и дискретности суммирования. Предложенный метод коррекции дает возможность получить необходимые для осуществления оптимальной модуляции функциональные преобразоования. Секция отметила перспективность оптимальной модуляцин, как нового метода, позволяющего значительно повысить эффективность радиопередач.

В докладе А.Г. Қислякова (Горький) «O чувствительности измерителей слабых спгналов со сплошным спектром» 
были изложены результаты проведениого нсследования приемников слабых сигналов со сплошным спектром различных типов.

Секция закончила свою работу докладом И. А. Фастовского (Ленинград): «Прибор для анализа радиопомех».

На секции полупроводников и их применения в радиоаппаратуре было заслушано 17 докладов и сообщений,

Ряд докладов относился к физическим свойствам полупроводников.

В докладе В. Е. Лашкарева, Р. $М$ Бондаренко, В. Н. Добровольского, В. Г. Литовченко, Г. П. Зубрина, В. И. Стрихи (Киев) рассматривались «Электрические и рекомбинацнонные свойства германия с примесью бериллия» в широком диапазоне концентраций.

В докладе В. Н. Вертопраховой (Томск) «Анизотропия некоторых свойств монокрнсталлов германия» показано, что фото-магиитные эффекты в монокристаллах германия существенно зависят от состояния поверхности образца.

Доклад А. П. Вяткина (Томск) «Исследование свойств контактов германил с металлами и сплавами» был посвяшен изучению продесса образования и формы сплавного контакта германия с индием? в зависимости от кристаллографической ориентации поверхности германия и других факторољ.

«Исследование темперагурной зависииости шумов германия» явилось предметом доклада В. В. Потемкина и Чукнnoй Г. А. (Москва), в котором рассматривался избыточный шум, проявляюшнйся на низких частотах и затрудняющнй усиление слабых сигналов.

Результаты теоретического построения обобщенных модуляционных характери-

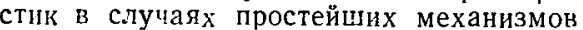
фотопроводимости люминесценции были изложены в доклале, В. А. Малышева (Таганрог) «Теория модуляционных свойств фотосопротивления и люминофоров».

В докладе Н. С. Спиридонова (Киев) рассматривались «Частотные свойства дрсйфовых полупроводниковых триодов».

Исследованное Н. В. Александров!мм, Л. Б. Горской, Е. М. Гершензоном, В. С. Эткиным (Москва) «Влия ние германиевой пластинки на распро странение волн, в волноводе» показало, что пропускание тока по гермапиевой пластинке, расположенной в волноводе, дает возможность управлять амплитудой и фазой электромагнитной волны

Остальные доклады были посвящены различному применению полупроводников в радиоаппаратуре.

Е. Ф. Доронкин (Қиев) изложил «Расчет схем температурной компенсацин полупроводниковых релаксационных генераторов».

«Анализ полупроводниковых генераторов линейно-изменяюшегося напряжения фантастронного типа» был рассмотрен Б. В. Воскресенским (Киев). А. Н.
Якунькиным (Саратов) сделано сообщение «К вопросу о механизме возбуждения колебаний высокочастотного генератора на точечном полупроводниковом приборе».

В докладе С. $M$. Герасимова (Киев) были приведены результаты работы «Исследование автогенераторов на составных полупроводниковых трнодах».

Темой доклада И. Н. Мигулина (Киев) было «Исследование некоторых схем полупроводниковых усилителей».

O способах повышения стабильности усилителя постоянного тока на полупроводниковых триодах доложил С. И. Малашенко (Киев)

Г. И. Олифиренко (Москва) в докладе «Полупроводниковые триоды в генераторе строчной развертки» привел результаты теоретических и экспериментальных исследований, выполненных автором в этой области.

«Исследование некоторых методов стабилизации частоты в полупроводннковых автогенераторах» явилось предметом доклада Б. П. Беспалова (Қиев).

Секция закончила свою работу докладом Е. К. Васильева (Москва) «Явление «смыкания» переходов в полупроводниковом триоде и некоторые его применения».

На заключительном пленарном заселании 27 января присутствующие с большим интересом выслушали доклад чл.-корр. АН СССР В. И. Сифорова «Проблема каналов связи со случайными изменениями параметров».

Вторьм сообшением обзорного характера на пленарном заседании. был доклад И. А. Кукурите, Г. И. Рукмана, О. Я. Савченко, $M$. K. Сафонова, Г. M. Халланова (Москва): «Перспек тивы использования некоторых оптикорадиофнзических явлений для создания новых приборов сверхвысоких частот», в котором рассматрнвались возможные применения оптико-физических приборов, использующих малую инерционность эффектов Фарадел, Кэрра н др. явления, в которых переменные поля воздействуют на оптические свойства вещества.

$$
* \text {; * }
$$

В решениях конференции подчеркивастся необходимость созыва междуведомственных, а также специализирован ных конференций по вопросам радиофнзики нІ электроники.

В связи с введением в вузах производственного обучения студентов конференция считает необходимым дальнейшее укрепление материальной базы вузовских лабораторий.

Конференция наметила наиболее актуальные направления дальнейших исследований.

$B$ области общей электроники в связи с запросами современной техники шире вести исследования оптики заряженных пучков, плазмы газового разряда. 
B области электродинамики СВЧ В дальнейшей научно-исследовательской работе уделить особое внимание быстрейшему освоению новых диапазонов радиоволн; разработке методики расчета и конструирования элементов СВЧ алпаратуры для высоких уровней мощности; исследованию возможности расчета и создания широкодиапазонных деталей и узлов аппаратуры и разработке методов радиоизмерений на СВЧ.

Наряду с дальнейшим развитием строгих методов электродинамических расчетов СВЧ систем и на их основе разрабатывать упрощенные инженерные методы с доведением результатов до таблиц, графиков и номограмм.

В области радиоастрономии и распространения радиоволн. Объем исследоваиий, которые проводятся в учреждениях недостаточен; работы недостаточно координированы; увеличение объема исследований и расширение тематнки идет весьма медленно. Это обстоятельство замент но, если сравнить соответствующие разделы программ текущей и II Саратовской конференций МBO СССР.

$B$ области электродинамики $С B Y$ Конференция отмечает расширение фронта исследований новых методов усиления и генерирования на основе фазохронного взанмодействия быстрых и пространственных гармоник электронных пучков с полем, параметрического взаимодействия, а также методов повышения эффективности уже известных приборов.

Конференция рекомендует продолжить теоретические и экспериментальные исследования в этом направлении с учетом нелинейных явлений. При этом особое внимание обрашается на разработку малошумяших параметрических приборов и генераторов большой мощности для связи и других целей.

В области квантовой радиофизики и paduоспектроскопии. Конференция отмечает актуальность исследований, ведущихся вузами в области квантовых явлений в радиофизике и по параметрическим системам, но высшие учебные заведения еше мало уделяют внимания перспективным и весьма актуальным проблемам в этой области.

Конференция считает целесообразным дальнейшее развитие этих работ в ву-

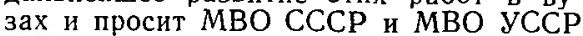
войти в Комиссию по ферромагнетикам (К. M. Поливанов) и ферритам (А. А. Пистолькорс) с просьбой о включении в общий план АН CCCP и Государственного Комитета по радиоэлектронике работ, ведущихся в вузах.

Поступнла в редакцию 10 II 1959 г.
Конференция просит МВО СССР, МВО УССР и Гос. комитет по радиоэлектронике оказывать содействие вузам в развитии работ по квантовой радиофизике и радиоспектроскопин.

Конференция обращает внимание на важность исследований вопросов взаимодействия ультразвука со спиновыми волнами воздействия ультразвука на ферриты.

В области общей радиотехники. Kонференция считает, что в настоящее время общее состояние научно-исследовательских работ по оитимальной амплитудно-фазовой модуляции настоятельно требует объединения усилий работников науки и практики в целях эксплуатационной проверки новой системы модуляции.

Конференция считает целесообразным рекомендовать Министерству связн УССР в ближайшее время перевести на оптимальную амплитудно-фазовую модуляцию одну из радиовещательных станций с целью накопления практического опыта для широкого внедрения новой системы модуляции в народное хозяйство страны.

$B$ области полупроводниковых приборов и их применения. Конференция счнтает целесообразным дальнейшее развитие теории усиления и генерирования колебаний на новейших типах полупроводниковых приборов и отмечает необходимость усиления работ в области разработки новых прнборов. Конференция считает необходимым обратить внимание Гос. комитета по радиоэлектронике при Совете Министров СССР на необходимость дальнейшего усовершенствования технологии производства полупроводниковых приборов с минимальным разбросом параметров.

Отмечая важное значение вопросов повышения надежности радиотехнической аппаратуры и ее элементов, конференция просит $\mathrm{MBO}$ СССР и $\mathrm{MBO}$ УССР рассмотреть вопрос об организацин факультативных курсов по на дежности радиоаппаратуры на радиотехнических факультетах не позднее 1959-1960 гг.; поручить группе специалистов подготовить в кратчайший срок учебные пособия по теории надежности; широко рекомендовать дипломантам вузов и аспирантам темы, связанные с теоретическими и практическими вопросами надежности радиоаппаратуры.

IV Всесоюзную конференцию МВО СССР по радиофизике и электронике (с секциями: радиоизмерений, электродинамики СВЧ, электроники СВЧ, надежности радиоаппаратуры) намечено провести в г. Харькове (Харьковский государственный университет) в ноябре 1960 r.

Инж. Лянной $В . П$. 